\title{
Enhancement of Nutritional Quality of Wheat (Triticum aestivum) by Metabolic Engineering of Isoflavone Pathway
}

\author{
${ }^{1,2}$ Ahmed Mohamed El-Shehawi, ${ }^{1,3}$ Abdelmegid Ibrahim Fahmi, \\ ${ }^{2}$ Mona Mohamed Elseehy and ${ }^{1,3}$ Hesham Ahmed Nagaty \\ ${ }^{1}$ Department of Biotechnology, Faculty of Science, Taif University, Taif, Saudi Arabia \\ ${ }^{2}$ Department of Genetics, Faculty of Agriculture, University of Alexandria, Elshatby, Alexandria, Egypt \\ ${ }^{3}$ Department of Genetics, Faculty of Agriculture, Menoufia University, Shebin El-Kom, Egypt
}

Received 2013-07-23; Revised 2013-10-05; Accepted 2013-10-22

\begin{abstract}
Isoflavones are large group of secondary metabolites produced in legumes such as soybeans. They have essential biological functions as nutraceutical and health functions for human. They are involved in plant resistance to biotic and abiotic stresses, symbiotic relationship with nitrogen-fixing organisms and plant competition (allelopathy). In this report, isoflavonoids were expressed in wheat (Triticum aestivum) via introducing the key enzymes Isoflavone Synthase (IFS). Transgenic calli induced from wheat immature embryos were propagated and prepared for bombardment. Five gene constructs were prepared; the binary vector (plasmid) pAHC25, 35S-CRC, 35S-IFS, Oleocin-IFS, Oleocin-IFS-CHI and were used for wheat calli transformation. Putative transgenic calli were used to regenerate transgenic wheat plants. Evaluation of recovered transgenic plants was carried out using PCR, southern bloting of PCR products and IFS-specific probe and HPLC analysis of transgenic plant tissue extracts. Genistein and naranigenin were detected in transgenic plants carrying IFS gene, indicating that the introduced IFS was able to use the endogenous substrate from wheat. IFS showed activity under $35 \mathrm{~S}$ promoter as well as oleocin promoter. The activity of oleocin promoter in monocots provides a good tool to use plant promoters to drive plant gene expression in plants. This also represents promoter compatibility that the cis acting elements of the oleocin promoter represent binding targets for trans acting elements of wheat. Engineering the isoflavone pathway in wheat would lead to enhancement of nutraceutical value of wheat grains and improvement of wheat resistance to diseases.
\end{abstract}

Keywords: Wheat, Transgenic, Isoflavnoids, HPLC, PCR

\section{INTRODUCTION}

Wheat is the world's second largest crop, behind maize and is one of the most important foods for the world. However, wheat and other cereals are poor sources of all human nutrients because they lack many of non-essential micronutrients such as various phytochemicals (Ferrreyra et al., 2012; Wang, 2011; Du et al., 2010). Most of these bioactive components are plant secondary metabolites and can be genetically engineered to staple crops such as wheat to improve food quality and develop functional foods. For example, 'Golden rice' was genetically engineered to enhance the levels of beta-carotene (the precursor to vitamin A) to prevent blindness in developing countries (Ye et al., 2000). Several health promoting components such as human milk proteins in rice (Lonnerdal, 2002), high phytosterol vegetable oil (Venkatramesh et al., 2000), high lycopene in tomatoes (Romer et al., 2000), high flavonoids in tomatoes (Muir et al., 2001; Sevenier et al., 2002) and high isoflavones in soybeans (Jung et al., 2000; Yu et al., 2003) were genetically engineered to produce nutritional and functional food.

Isoflavones are secondary metabolites produced predominately in leguminous plants such as soybean. Saudi Arabia 
Isoflavones play an important role in plant-microbe interactions and disease resistance response (Arango et al., 2013; Ferrreyra et al., 2012; Mandal et al., 2010). They act as chemoattractants for the rhizobial bacteria and as inducers of nod gene expression (Arango et al., 2013; Prasad et al., 2010; Crozier et al., 2009) during the symbiotic relationship between the plant and rhizobial bacteria for the formation of nitrogen-fixing root nodules. The isoflavone daidzein is the precursor to the major phytoalexins including medicarpin and glyceollins, which are produced in alfalfa and soybean, respectively (Ferrreyra et al., 2012; Blount et al., 1992). The isoflavone genistein, the precursor to the phytoalexin kievitone (Mandal et al., 2010; GarciaArenal et al., 1978), exhibit antifungal activity (Mandal et al., 2010). There is also evidence for a role for isoflavones in human health as a dietary component (Arango et al., 2013; Ferrreyra et al., 2012).

Isoflavones is associated with health benefits such as decreased risk of heart disease (Arango et al., 2013; Ferrreyra et al., 2012), reduced menopausal symptoms (Ferrreyra et al., 2012; Du et al., 2010) and reduced risk of some hormone-related cancers (Ferrreyra et al., 2012; Du et al., 2010). Various reports indicate that soy products may be helpful both in preventing cancer and in helping to treat it (Arango et al., 2013; Ferrreyra et al., 2012; Prasad et al., 2010).

The active component of soybean that is thought to be primarily responsible for this beneficial action is genistein. The amount of isoflavones in soybean seed can vary up to five fold (Eldridge and Kwolek, 1983) and vary by year, environment and genotype. In addition, isoflavone content in legumes can be stress-induced by pathogenic attack, wounding, high UV light exposure and pollution (Arango et al., 2013; Ferrreyra et al., 2012; Verdan et al., 2011).

Other studies to enhance the nutrition quality of plant products have been successful. The carotenoid (antioxidant) concentration has been enhanced in $B$. napus seeds via suppressing the BnDETl gene (Wei et al., 2009). The Arabidopsis MYB regulatory gene AtPAP1 (Production of Anthocyanin Pigment 1) was overexpressed in B. napus (canola) for the production of anthocyanin and developed the "Purple Canola" which has antioxidant activity about four fold higher in its leaves (Li et al., 2010).

Cloning of IFS gene provided the opportunity for metabolic engineering to influence isoflavone synthesis in legumes and non-legumes (Yu et al., 2000; 2003; Liu et al., 2002; 2007; Sreevidya et al., 2006; Li et al.,
2011). Expression of IFS gene in Arabidopsis using a strong constitutive promoter resulted in the production of genistein. Arabidopsis does not have IFS and does not make isoflavones, but it does produce the IFS substrate naringenin, which is normally involved in the production of anthocyanins and condensed tannins (Ferrreyra et al., 2012; Rimando et al., 2012). In the same study, genistein and daidzein were expressed in tobacco (Nicotiana tabacum) plants and maize (zea mays) cell system (Rimando et al., 2012). Soybean IFS was overexpressed in soybean to increase isoflavones in its seeds (Yu et al., 2003). Also, IFS from soybean was used to produce transgenic Brassica napus plants (Li et al., 2011). The isoflavone genistein was expressed in tobacco, lettuce and petunia (Liu et al., 2007). This number of studies demonstrated the feasibility of metabolic engineering of IFS for the production of isoflavones in agronomically important plants. In cereal plants, isoflavone metabolic pathway was engineered in rice to produce these novel compounds and induce nodulation genes (Zhang et al., 2009). Wheat, which does not produce isoflavones, is one of the major food staples of humans. Synthesis of isoflavones in wheat may enhance its nutritional value and consequently reduce the chronic diseases such as cardiovascular disease in human (Arango et al., 2013). In this study, we engineered wheat to produce isoflavones using IFS gene under $35 \mathrm{~S}$ as well as soybean oleocin promoters.

\section{MATERIALS AND METHODS}

\subsection{Callus Induction of Wheat Immature Embryos}

Wheat varieties were planted and maintained in the green house. Calli were initiated from immature embryos of wheat varieties (Fig. 1a and b). Immature seeds were surface sterilized in $70 \%(\mathrm{v} / \mathrm{v})$ ethanol for $1 \mathrm{~min}$ and subsequently in $1.0 \%(\mathrm{w} / \mathrm{v})$ sodium hypochlorite for 15 min. They were rinsed three times with sterilized water. Immature embryos were isolated and cultured on MS medium modified for wheat callus induction (Murashige and Skoog, 1962) solidified with $2.5 \mathrm{~g} \mathrm{~L}^{-1}$ phytagel (Sigma, St Louis, MO) containing MS vitamins, $150 \mathrm{mg} \mathrm{L}^{-1}$ asparagine, $2 \mathrm{mg} \mathrm{L}^{-1} 2,4-\mathrm{D}, 100 \mathrm{mg} \mathrm{L}^{-1}$ myo-inositol, $20 \mathrm{~g} \mathrm{~L}^{-1}$ sucrose. The cultures were incubated in the dark at $24^{\circ} \mathrm{C}$. After 3 weeks of culture, embryogenic calli derived from immature embryos were propagated twice on the same media and conditions to prepare enough calli for bombardment. 


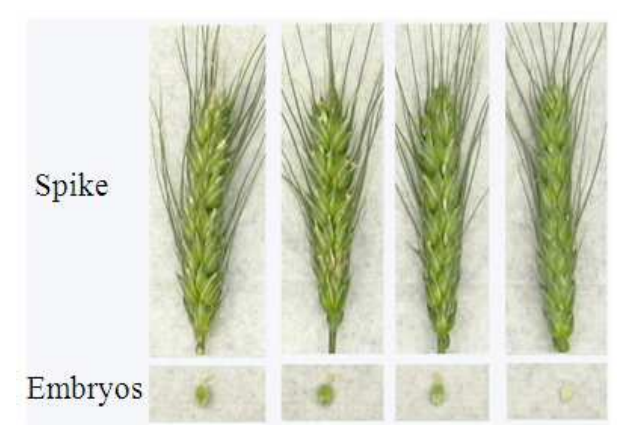

(a)

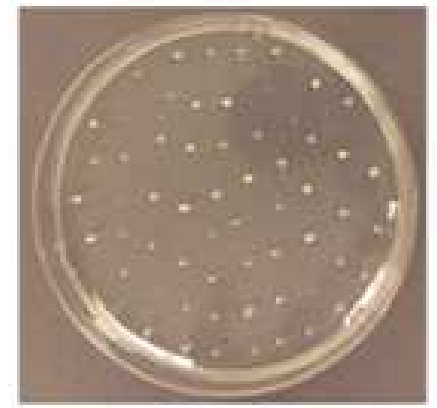

(b)

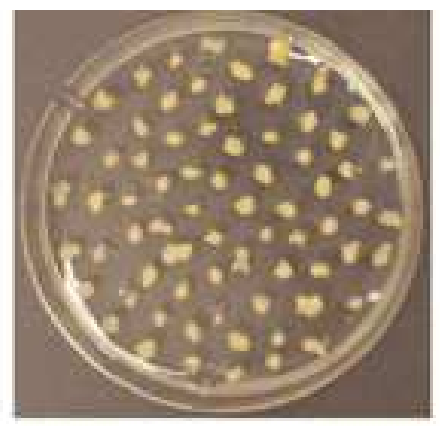

(c)

Fig. 1. (a) Wheat (Triticum aestivum) spikes at 14 days of anthesis and the corresponding embryos used for isolation of immature embryos for callus induction; (b): Wheat (Triticum aestivum) immature embryos on MS media for callus induction; (c): Calli induced from immature wheat (Triticum aestivum) embryos on MS media

\subsection{Preparation of Gene Constructs}

IFS gene constructs were kindly provided by Dr. Oliver Yu (Danforth Plant Science Center). He also provided the DNA plasmid pAHC25 (Christensen et al., 1992). pAHC25 consists of the uidA gene encoding $\beta-$ Glucuronidase (GUS) and the bar gene encoding Phosphinothricin Acetyltransferase (PAT) that inactivates Phosphinothricin (PPT), active ingredient of the herbicide glufosinate. Transcription of uidA and bar genes is under the control of the maize ubiquitin Ubil promoter (Christensen et al., 1992). The transcription factor CRC was used under the control of $35 \mathrm{~S}$ promoter to enhance the expression of the transferred genes and other genes in the phenylpropanoid pathway. These constructs were transformed into E. coli and maintained for plasmid isolation for bombardment (Fig. 2).

\subsection{Particle Bombardment}

Microcalli were placed in the center of $9 \mathrm{~cm}$ diameter Petri dishes containing MS medium solidified with $2.5 \mathrm{~g}$ $\mathrm{L}^{-1}$ phytagel, supplemented with $0.4 \mathrm{M}$ manitol for $4 \mathrm{~h}$. The microcalli were immediately subjected to microprojectile bombardment with the Biolistic Particle Delivery PDS-1000/He system (Bio-Rad). Gold particles $(1.0 \mu \mathrm{m})$ were coated with the plasmid DNA as per the published procedure (Manoharan and Dahleen, 2002). Three milligrams ( $3 \mathrm{mg}$ of $1.0 \mu \mathrm{m}$ diameter) of gold particles was sterilized in $100 \mu \mathrm{L}$ absolute ethanol for $2 \mathrm{~min}$ with vortexing. After washing with sterile water twice, particles were resuspended in $100 \mu \mathrm{L}$ sterile water. The mixture was prepared as follows: 100 $\mu \mathrm{L}$ of particle suspension were mixed with $5 \mu \mathrm{L}(1 \mu \mathrm{g}$ $\left.\mu \mathrm{L}^{-1}\right)$ of plasmid DNA, $50 \mu \mathrm{L} \mathrm{CaCl}_{2}(2.5 \mathrm{M})$ and $20 \mu \mathrm{L}$ spermidine $(0.1 \mathrm{M})$. The particle/DNA suspension was vortexed and left for $10 \mathrm{~min}$ at room temperature. The DNA coated particles were pelleted by centrifugation at $10,000 \mathrm{rpm}$ for $10 \mathrm{sec}$. The supernatant was completely removed and discarded. The pellet was then resuspended in $60 \mu \mathrm{L}$ absolute ethanol. Particle/DNA mixture $(8 \mu \mathrm{L})$ was placed in the center of microcarrier. The target cells were placed at a distance of $8 \mathrm{~cm}$ from the screen and directly covered with a baffle $(500 \mu \mathrm{m}$ stainless steel mesh). Calli on each plate were bombarded once at 1300 psi. Different combinations of gene constructs were used in the bombardement of wheat calli (Table 1).

\subsection{Propagation and Testing of Transgenic Calli}

Following bombardment, calli were kept on the osmotic media for 16 more hours and then transferred to MS media for 2 days for recovery. Bombarded calli were transferred to selection media containing $3 \mathrm{mg}$ $\mathrm{L}^{-1}$ biolaphos. Calli were subcultured twice on the same selection media in the dark. Samples of transgenic calli were analyzed by PCR. Genomic DNA was isolated from transgenic calli according to Dellaporta et al. (1983). IFS-specific primers (Forward: ATGTTGCTGGAACTTGCACT, Reverse: GCGCTTTGGGCCATAACCCT) were used to amplify $500 \mathrm{bp}$ of IFS gene in the putative transgenic calli. Amplified products were electrophoresed on $1.0 \%$ agarose-ethidium bromide gels and observed under UV light. 

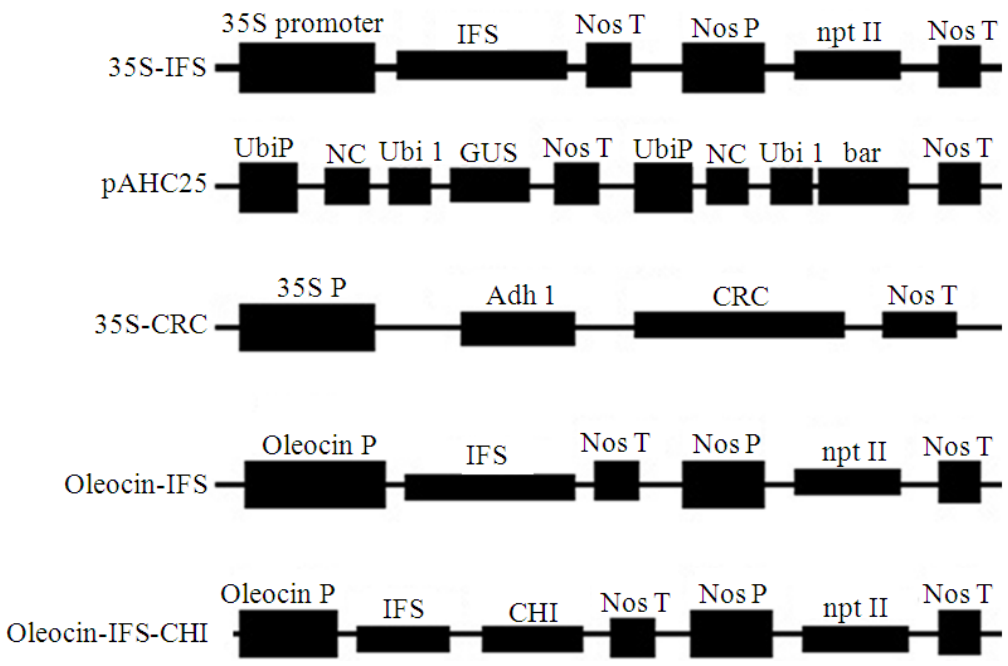

Fig. 2. Molecular map of gene constructs that were used in bombardment of wheat calli

Table 1. Summary of gene construct combinations used in transformation of wheat calli. More details about these constructs are showed in Fig. 2

\begin{tabular}{lllll} 
& & & O-IFS & O-IFS-CHI \\
\hline 35 S-BAR & 35 S-CRC & 35S-IFS & & \\
+ & + & & & \\
+ & + & & + & + \\
+ & + & & & \\
+ & + & & & \\
\hline
\end{tabular}

\subsection{Regeneration of Transgenic Plantlets}

Survived transgenic calli were transferred to regeneration media (same $\mathrm{MS}$ with $0.2 \mathrm{mg} \mathrm{L}^{-1}$ 2,4,D; MMS0.2) supplemented with $3 \mathrm{mg} \mathrm{L}^{-1}$ bioalaphos for two-three weeks or shoot emergence, then transferred to MMS0 (same MS with $0 \mathrm{mg} \mathrm{L}^{-1}$ 2,4,D) supplemented with $1 \mathrm{mg} / \mathrm{L}$ biolaphos for another two weeks or root emergence in the light (fluorescent light (3.1-5.5 $\mu \mathrm{moL} / \mathrm{m}^{2}$ per second) at $\left(24-26^{\circ} \mathrm{C}, 16 / 8 \mathrm{~h}\right.$ day/night $)$. Green shoots usually develop within 2-3 weeks on the regeneration medium. The regenerated shoots were transferred to rooting medium (half-strength MS) with 3 $\mathrm{mg} \mathrm{L}^{-1}$ bialaphos. Fully developed plants were transferred to peat pellets and then to pots in the greenhouse $\left(21-26^{\circ} \mathrm{C}, 16 / 8 \mathrm{~h}\right.$ (day/night) photoperiod with natural lighting supplanted with sodium vapor lamps). Transgenic plants were tested by PCR using the same IFS-specific primers and conditions above.

\subsection{Molecular Characterization of Transgenic Plants}

\subsubsection{RNA Analysis}

Expression of IFS gene at transcriptional level was confirmed by reverse transcription followed by PCR (RT-PCR). Total RNA was isolated from transgenic plants using TRI REAGENT (Molecular Research Center). Reverse specific primer (Reverse: GCGCTTTGGGCCATAACCCT) for IFS was used to synthesize the first strand of cDNA. Specific forward and reverse primers for IFS (Forward: ATGTTGCTGGAACTTGCACT, reverse: GCGCTTTGGGCCATAACCCT) were used to amplify $500 \mathrm{bp}$ diagnostic fragments of IFS transgene to confirm its transcription.

\subsubsection{Southern Blotting}

Southern blotting was carried out according to Hedgcoth et al. (2002). Five $\mu \mathrm{L}$ of PCR product was separated on agarose and transferred to a positively charged Nylon membrane. A DNA probe of the IFS coding region was prepared by PCR using the same IFSspecific primers that were used in PCR amplification (Forward: ATGTTGCTGGAACTTGCACT, Reverse:GCGCTTTGGGCCATAACCCT). The probe was labeled with digoxigenin-11-dUTP (Rathburn et al., 1993) for chemiluminescent detection following hybridization of a Southern blot.

\subsubsection{HPLC of Isoflavones}

For isoflavone quantification and analysis, plant tissues were ground in liquid nitrogen, extracted with 
$80 \%(\mathrm{v} / \mathrm{v})$ methanol at $100 \mathrm{mg} \mathrm{ML}^{-1}$ and filtered through syringe filters. To hydrolyze any possible isoflavone conjugates, $3 \mathrm{~mL}$ of $1 \mathrm{~N} \mathrm{HCl}$ were added to $1 \mathrm{~mL}$ of the extract and the samples were incubated at $95^{\circ} \mathrm{C}$ for $2 \mathrm{~h}$, followed by extraction using $1 \mathrm{~mL}$ ethyl acetate. The HPLC conditions were similar to that previously used by Jung et al. (2000). Samples were assayed on HPLC Agilent Model 1100 system on a Phenomenex Luna C18 column $(4.6 \times 250 \mathrm{~mm}, 10 \mu)$, separated by using a $12 \mathrm{~min}$ linear gradient from $20 \%$ methanol $/ 80 \% \quad 50 \mathrm{mM}$ ammonium acetate (pH 5.9) to $100 \%$ methanol at a flow rate of $2 \mathrm{~mL} \mathrm{~min}^{-1}$ with oven temperature of $35^{\circ} \mathrm{C}$ and injection volume of $10 \mu \mathrm{L}$. Genistein and naringenin were monitored by A290. For calibration, authentic compounds were dissolved in ethanol and used as standards. Peak areas were converted to micrograms.

\section{RESULTS}

Wheat immature embrys (Fig. 1b) were excised from wheat inflorescence 14 days after anathesis (Fig. 1a) and used for callus induction on MS media. Calli were propagated and prepared for bombardement (Fig. 1c)

Five gene constructs were used in bombardement of wheat calli Fig. 2. The binary vector pOY204, which contains a chimeric gene consisting of the cauliflower mosaic virus $35 \mathrm{~S}$ promoter, the soybean IFS1 coding region and the nopaline synthase terminator (Nos 39), together with an nptII gene cassette for kanamycin selection in plants (Jung et al., 2000). Plasmid pAHC25 (Christensen et al., 1992). It contains the uidA gene encoding B-Glucuronidase (GUS) and the bar gene encoding Phosphinothricin Acetyltransferase (PAT) that inactivates Phosphinothricin (PPT), active ingredient of the herbicide glufosinate. Transcriptions of uidA and bar genes are under the control of the maize ubiquitin Ubil promoter (Christensen et al., 1992). One construct of the transcription factor CRC which include $35 \mathrm{~S}$ promoter, Adh1 intron 6, CRC coding region and Nos terminator was used to enhance the expression of the transferred genes ( $\mathrm{Yu}$ et al., 2000). The construct Oleocin-IFS contains the IFS gene under the control of soybean oleocin promoter, Nos terminater and NptII gene under the control of Nos promoter and Nos terminator. The construct OleocinIFS-CHI contains a chimeric gene of IFS1 and CHI from soybean under the control of oleocin promoter, Nos terminater and NptII gene under the control of Nos promoter and Nos terminator.

\subsection{Callus Transformation and Transgenic Plants Regeneration}

Combinations of the five constructs described above were used in transforming wheat calli (Table 1). Many putative transgenic calli were recovered and propagated. A number of transgenic plantlets were regenerated, grown and maintained (Fig. 3).

\subsection{Molecular Characterization of Transgenic Plants}

Specific primers of IFS gene were used to amplify DNA fragment of $500 \mathrm{bp}$ of the $5^{\prime}$ end of IFS gene. Many transgenic plants were tested using RT-PCR for transcription of the IFS gene. Forty three positive transgenic plants (Table 2) were tested of which 23 are shown in Fig. 4. Southern blotting was carried out using the PCR product amplified from transgenic plants and IFS-specific DNA probe. Thirty six transgenic plants of which 11 transgenic lines $(1,3,4,6,9,10,11,14,17,18,21)$ gave strong signal on southern blot (Fig. 5), three plants $(5,8,16)$ gave weak signal and 7 plants $(2,7,12,13,15,19,20)$ gave no signal. Only plants with strong signals were used as transgenic lines and used for more analysis (Fig. 5).

\subsection{Progeny Analyses of Transgenic Plants}

Concentrations of naringenin and genistein varied in the recovered transgenic plant seeds. There were some low and high expressers of the IFS gene in wheat plants under both $35 \mathrm{~S}$ and oleocin promoters. Genistein showed high accumulation in some transgenic plant lines (Table 2). This indicates the high activity of the exogenous IFS in turning over the endogenous nagingenin into genistein competing for nagingenin conversion into anthocyanins. The seeds of low genistein accumulators showed normal color. Only constructs 35S-IFS and O-IFS showed genistein, whereas it was not detected in O-IFS-CHI transgenic seeds. It seems the chimeric gene IFS-CHI was not functional in wheat or metabolic channeling by the endogenous CHI and IFS was more competitive than the heterologous ones. The tested lines showed various concentrations of genestein. Naringenin concentrations range was $0.7-3.54 \mu \mathrm{g} \mathrm{mL}^{-1}$ in 35S-IFS plants, whereas its range was $1.13-3.13 \mu \mathrm{g} \mathrm{mL}^{-1}$ in the O-IFS plants. Its average was 2.20 and $2.58 \mu \mathrm{g} \mathrm{mL}^{-1}$ in $35 \mathrm{~S}$-IFS and $\mathrm{O}$ IFS plants consecutively. Genistein concentrations ranged from $4.8 \mu \mathrm{g} \mathrm{mL}^{-1}$ to $35.14 \mu \mathrm{g} \mathrm{mL}^{-1}$ in $35 \mathrm{~S}$-IFS plants, whereas it ranged 9.81-44.61 in the O-IFS plants. Its average was 20.64 and 29.29 in $35 \mathrm{~S}$ and O-IFS plants consecutively (Table 2 and Fig. 6). 
Ahmed Mohamed El-Shehawi et al. / American Journal of Biochemistry and Biotechnology 9 (4): 404-414, 2013

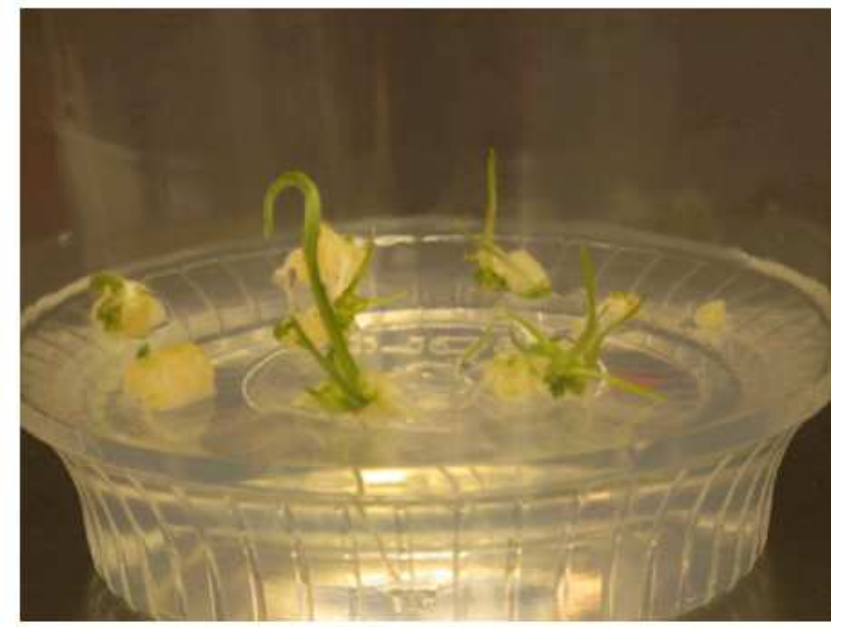

Fig. 3. Regenerated shoots of transgenic wheat plantlet on regeneration medium

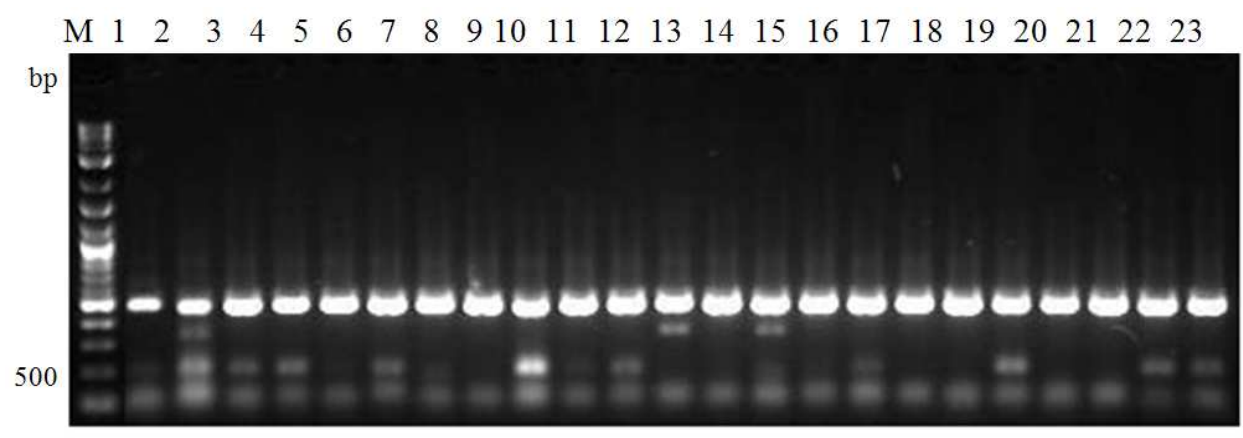

Fig. 4. RT-PCR amplification of $500 \mathrm{bp}$ from IFS gene from 23 wheat transgenic plants

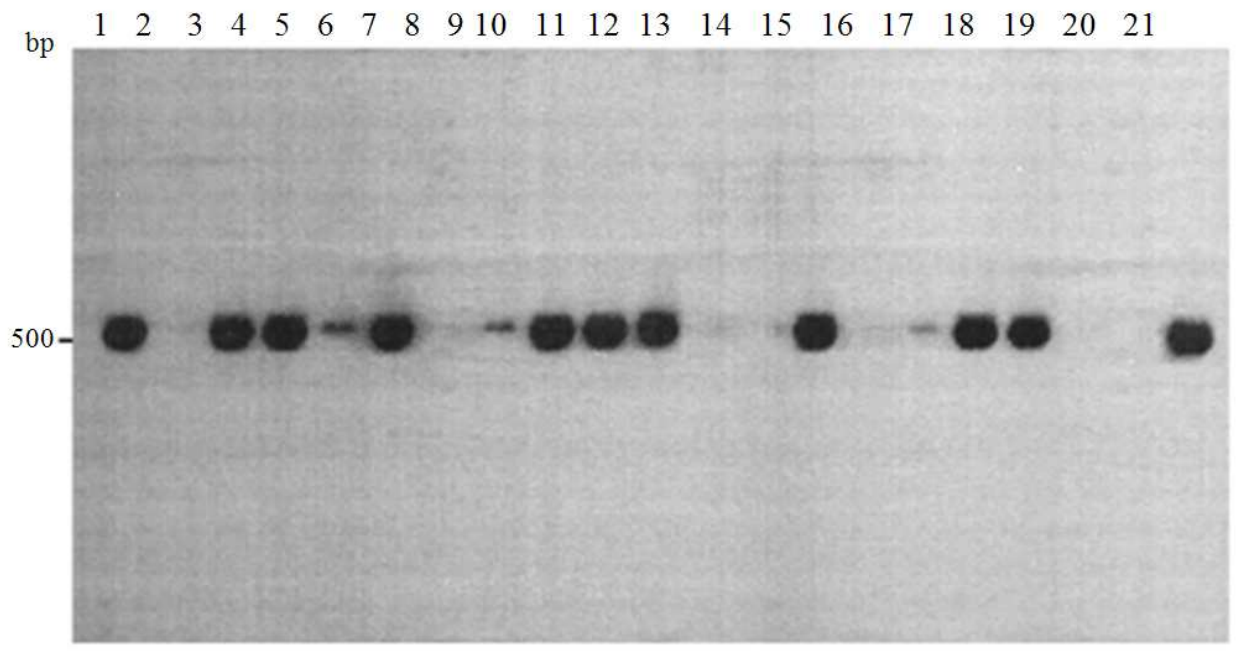

Fig. 5. Southern blot analysis of PCR products of representative transgenic plants 
Ahmed Mohamed El-Shehawi et al. / American Journal of Biochemistry and Biotechnology 9 (4): 404-414, 2013

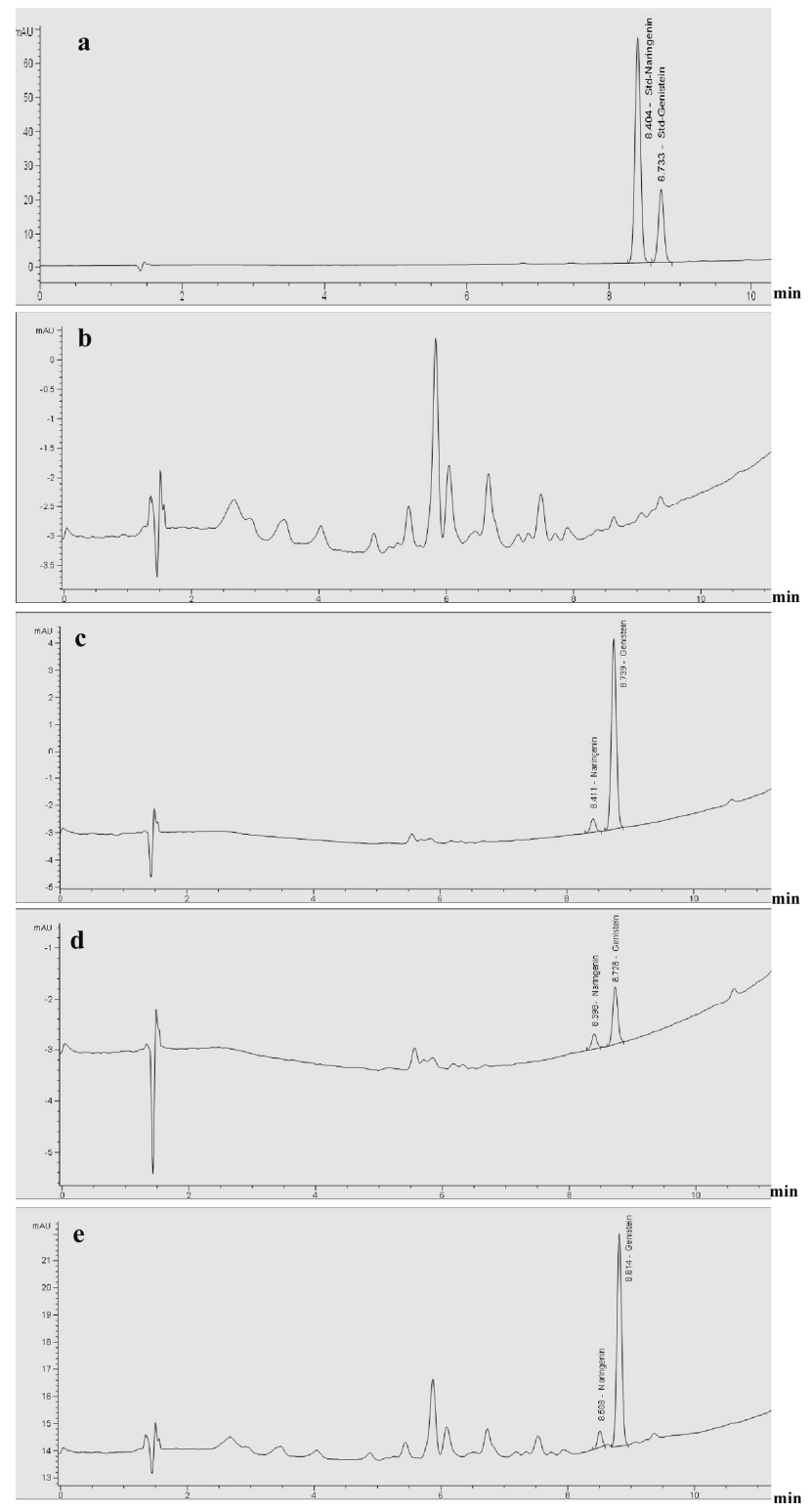

Fig. 6. HPLC estimation of nagingenin and genestein of (a) standard mix (nagingenin and genestein); (b) negative control; (c), (d), (e), representative transgenic plants

Table 2. Summary of recovered transgenic wheat plants and their characteristics

\begin{tabular}{llll} 
& Construct & & \\
& $-35 \mathrm{~S}-\mathrm{IFS}$ & O-IFS & Total \\
\hline No of trangenic plants & 29 & 14 & 43 \\
No of tangenic plants tested by Southern & 20 & 9 & 36 \\
No of tangenic plants tested by HPLC & 14 & 2.58 & 23 \\
Naringenin concentration $($ average, $\mu \mathrm{g} / \mathrm{mL})$ & 2.20 & $1.13-3.13$ & - \\
Naringenin range, $\mu \mathrm{g} / \mathrm{mL}$ & $0.7-3.54$ & 29.29 & - \\
Genistein concentration $($ average, $\mu \mathrm{g} / \mathrm{mL})$ & 20.64 & $9.81-44.61$ & - \\
Genistein range, $\mu \mathrm{g} / \mathrm{mL}$ & $4.80-35.14$ & \\
\hline
\end{tabular}




\section{DISCUSSION}

Wheat was genetically engineered by the key enzyme of isoflavone synthase under the control of $35 \mathrm{~S}$ promoter and soybean oleocin promoter. Direct introduction of DNA constructs into wheat calli derived from immature embryos was used. Transgenic plants were able to produce and accumulate genistein in wheat seeds giving some essential indications. First, the heterologous IFS was active in the wheat background and was able to use wheat endogenous substrate of nagingenin. Second, the oleosin promoter was active in wheat seeds. This promoter is seed-specific promoter from soybean. Its activity in wheat seeds is very interesting because it limits its expression to the seed tissue and can be used in similar studies in the future to drive the expression of other genes to replace viral promoter like 35S. In this study, it showed a leaky expression in some plant lines, especially in leaves (data not shown). Third, it provides the first report on the expression of isoflavone in wheat (second largest stable crop for food and feed after maize) in the world. Genistein accumulation varied greatly among our transgenic plants. Up to 9 fold differences in the accumulation of genistein in wheat seeds expressing soybean IFS under the control of $35 \mathrm{~S}$ as well as oleocin promoter were detected. Also, the IFS in some transgenic lines are more competitive to the $\mathrm{F} 3 \mathrm{H}$ gene for the naringenin substrate to the final product genistein. Other lines did not show this high competitiveness and they are considered low expressers of the transgene.

The low level of genistein has been discussed in several previous studies. This could be due to different scenarios. Metabolic chanallening has been reported to be one of the reasons. It has been accepted that the series of enzymes in flavonoid/isoflavonoid pathway form into an enzyme comblex called metabolon to improve its catalytic activity by channeling intermediates from upstream to downstream enzymes (Jorgensen et al., 2005; Yu et al., 2000). Therefore, the availability of the substrate for the foreign enzyme would be limited because it does not fit into the metabolon of the host enzymes or activity of other upstream enzymes in the metabolon is lower turning less substrate over for the IFS transgene (Liu et al., 2007). In our study, the CRC gene was used to activate other enzymes in the pathway to overcome the later problem (Yu et al., 2000; 2003), yet transgenic lines varied in the production and accumulation of genistein. In addition, the competition of IFS and $\mathrm{F} 3 \mathrm{H}$ for the narangenin substrate may vary in individual transgenic lines leading to different levels of genistein. It was reported that, cosupression of $\mathrm{F} 3 \mathrm{H}$ in soybean did not cause an increase of total isoflavone level in seeds (Yu et al., 2003). However, cosupression of $\mathrm{F} 3 \mathrm{H}$ resulted in enhancement of genistein content when maize transcription factor $\mathrm{CRC}$ was used to activate the anthoscyanin pathway. $\mathrm{Cl}$ and $\mathrm{R}$ transcription factors were used to increase the expression of isovlavone levels in soybean seeds (Glycine max) by metabolic engineering of the complex phenylpropanoid biosynthetic pathway. In this study, genistein was decreased and daidzein was increased with a small overall increase in total isoflavone levels. $\mathrm{C} 1 / \mathrm{R}$ expression and cosuppression of flavanone 3hydroxylase to block the anthocyanin branch of the pathway led to higher levels of isoflavones. This study concluded that, gene activation driven by transcription factor in conjunction with suppression of a competing pathway provided a successful strategy to enhance accumulation of isoflavones in soybean seed (Yu et al., 2003). Moreover, the low level of genistein in some transgenic lines could be explained by the low level of naringenin substrate (Sreevidya et al., 2006) or its channeling to flavonol biosynthesis. In our study, we detected varied level of naringenin ( 0.7 to $3.54 \mu \mathrm{g} \mathrm{mL}^{-1}$ ), while genistein level ranged from 4.8 to $44.61 \mu \mathrm{g} \mathrm{mL}^{-1}$ supporting the later scenario. Also, transgenic lines may have limited ability to store high level of genistein or turn it over to the glycosylated (stored) form.

Application of metabolic engineering of isoflavones is becoming more interesting and successful toward changing the nutritional and pharmaceutical value in many plant species. Several successful attempts have been done to engineer the isoflavonoids branch of phenylpropanoid into various plant groups including tomato (Shih et al., 2008), rice (Sreevidya et al., 2006), Arabidopsis (Liu et al., 2002) and oilseed rape B. napus (Li et al., 2011), dicots (Yu et al., 2000; Liu et al., 2007; Li et al., 2011), monocots (Sreevidya et al., 2006). Heterologous IFS enzyme from soybean was introduced in various non-legume dicot and monocot systems to evaluate its ability to interact with the endogenous phenylpropanoid pathway, which provides the substrate for IFS and produces genistein in several plant tissue systems. In tobacco (Nicotiana tabacum) genistein was increased in floral tissue that synthesizes anthocyanins, relative to leaves. In a monocot cell system (maize BMS cells), IFS was able to produce genistein when introduced a transcription factor regulating genes of the anthocyanin pathway. The cells were able to produce the isoflavone daidzein when the chalcone reductase gene was introduced. The genistein produced in 
tobacco, Arabidopsis and maize cells was present in conjugated forms, meaning that endogenous enzymes were capable of recognizing genistein as a substrate (Yu et al., 2000). The isoflavone genistein was produced in various tissues of Arabidopsis thaliana after the introduction of soybean isoflavone synthase (Jung et al., 2000). Isoflavone pathway was engineered in rice using soybean IFS. Generated transgenic plants were evaluated using PCR and southern blot analysis. IFS expression was documented by estimation of genistien in rice tissues. The results of this study confirmed that the IFS gene is active in transgenic rice plants. Genistein was present in the glycoside form, which means that endogenous glycosyl-transferases were able to recognize genistein as a substrate (Sreevidya et al., 2006). Brassica napus was engineered by the introduction of exogenous soybean IFS (Glycine max). The soybean IFS gene (GmIFS2) was introduced into $B$. napus plants, which was able to direct the synthesis and accumulation of genistein derivatives in leaves up to $0.72 \mathrm{mg} / \mathrm{g} \mathrm{dw}$. These results indicated that the heterologous GmIFS2 enzyme was able to use the $B$. napus naringenin as a substrate to produce genistein in oilseed rape (Li et al., 2011). Our results are consistent with other successful studies to express soybean IFS in rice (Sreevidya et al., 2006), tomato (Shih et al., 2008), Brassica napus (Li et al., 2011) and Arabidopsis (Liu et al., 2002) tobacco (Nicotiana tabacum) and maize (zea mays) cell system (Yu et al., 2000), soybean seeds (Yu et al., 2003), lettuce and petunia (Liu et al., 2007). In addition, a unique achievement was confirmed in this study that is using the oleocin promoter (plant promoter) to drive the plant gene IFS and getting the same level of gene expression under the control of the strong $35 \mathrm{~S}$ promoter used in all previous studies.

Soybean IFS was introduced into Arabidopsis to generate transgenic plants in which the $\mathrm{F} 3 \mathrm{H}$ gene (tt6/tt3 mutant) and HFR are impaired. This resulted in increased level of genistein (31-169 nmoL/g FW). F3H shares substrate naringenin with IFS and can compete for the same substrate. This could represent a limiting factor for genistein biosynthesis in transgenic plants (Liu et al., 2002). In our study, transfer of IFS from soybean into wheat (Triticum aestivum) under the control of $35 \mathrm{~S}$ promoter led to the accumulation of genistein in seeds, whereas the same gene expression under the oleosin promoter was limited to seeds with traces in some transgenic lines in other tissues. These results suggest that the exogenous soybean IFS was able to use the endogenous substrate naranigenin from wheat. This gives the chance to enhance the nutraceutical value of wheat grains through metabolic engineering of isoflavone branch in wheat.

According to our results and other studies, fluctuations in the IFS activity was very clear. Therefore, each transgenic line must be considered as an independent case because each one has been developed from a transformation and genomic insertion incident. Each insertion could be different regarding to the position of insertion of the gene and the microgenetic environment as well as the epigenome as a whole. Epigenome could modulate the expression of the transgene ranging from enhancing to silencing and anywhere in between. On the other hand, the heterologous enzyme has to compete with other endogenous enzymes that turn genistein over to other components in the phenylpropanoid pathway. The F3H competes for the naringenin and converts it to the final product anthocyanin (Yu et al., 2003).

\section{CONCLUSION}

The isoflavone pathway was engineered in wheat plant under the control of $35 \mathrm{~S}$ and oleocin promoter. The introduced IFS was able touse the endogenous wheat substrate to produce genistein and naranigenin under both $35 \mathrm{~S}$ promoter as well as oleocin promoter. The activity of oleocin promoter in monocots provides a good tool to use plant promoters to drive plant gene expression in plants. This represents promoter compatibility among cis acting elements of the oleocin promoter and trans acting elements of wheat at the gene regulation level. Engineering the isoflavone pathway in wheat will help to the improvement of nutraceutical value ofwheat grains and increase its resistance to diseases.

\section{ACKNOWLEDGEMENT}

The initial transformation was carried out at the Danforth Plant Science Center (St Louis, MO, 63132, USA). This work was supported by Taif University (Grant \# 1305-432-1).

\section{REFERENCES}

Arango, D., K. Morohashic, A. Yilmazc, K. Kuramochid and A. Pariharb et al., 2013. Molecular basis for the action of a dietary flavonoid revealed by the comprehensive identification of apigenin human targets. PNAS, 110: E2153-E2165. DOI: 10.1073/pnas. 1303726110 
Blount, J.W., R.A. Dixon and N.L. Paiva, 1992. Stress response in alfalfa (Medicago sativa L.): XVI. Antifungal activity of medicarpin and its biosynthetic precursors: Implications for the genetic manipulation of stress metabolites. Physiol. Mol. Plant Pathol., 41: 333-349. DOI: 10.1016/08855765(92)90020-V

Christensen, A.H., R.A. Sharrock and P.H. Quail, 1992. Maize polyubiquitin genes: Structure, thermal perturbation of expression and transcript splicing and promoter activity following transfer to protoplasts by electroporation. Plant Mol. Biol., 18: 675-689. PMID: 1313711

Crozier, A., J.B. Jaganath and M.N. Clifford, 2009. Dietary phenolics: Chemistry, bioavailability and effects on health. Nat. Prod. Rep., 26: 1001-1043. DOI: $10.1039 / \mathrm{b} 802662 \mathrm{a}$

Dellaporta, S.L., J. Wood and J.B. Hicks, 1983. Isolation of DNA from higher plants. PMB Reporter, 4: 19-21.

$\mathrm{Du}, \mathrm{H}$., Y. Huang and Y. Tang, 2010. Genetic and metabolic engineering of isoflavonoid biosynthesis. Applied Microbiol. Biotechnol., 86: 1293-1312. DOI: 10.1007/s00253-010-2512-8

Eldridge, A.C. and W.F. Kwolek, 1983. Soybean isoflavones: Effect of environment and variety on composition. J. Agric. Food. Chem., 31: 394-396. PMID: 6682871

Ferrreyra, M.L.F., S. P. Rius and P. Casati, 2012. lavonoids: Biosynthesis, biological functions and biotechnological applications. Front. Plant Sci., 3: 115. DOI: $10.3389 /$ fpls.2012.00222

Garcia-Arenal, F., A. Fraile and E.M. Sagasta, 1978. The multiple phytoalexin response of bean (Phaseolus vulgaris) to infection by Botrytis cinerea. Physiol. Plant Path., 13: 151-156.

Hedgcoth, C., A.M. El-shehawi, P. Wei, M. Clarkson and D.Tamalis, 2002. A chimeric open reading frame associated with cytoplasmic male sterility in alloplasmic wheat with Triticum timopheevi mitochondria is present in several Triticum and Aegilops species, barley and rye. Curr. Genet., 41: 357-365. PMID: 12185502

Jorgensen, K., A.V. Rasmussen, M. Morant, A.H. Nielsen and N. Bjarnholt et al., 2005. Metabolon formation and metabolic channeling in the biosynthesis of plant natural products. Curr. Opin. Plant Biol., 8: 280-291. PMID: 15860425

Jung, W., O. Yu, S.C. Lau, D.P. O'Keefea and J. Odell et al., 2000. Identification and expression of isoflavone synthase, the key enzyme for biosynthesis of isoflavones in legumes. Nat. Biotech., 18: 208-212. PMID: 10657130
Li, X., J. Qin, Q. Wang, X. Wu and C. Lang et al., 2011. Metabolic engineering of isoflavone genistein in Brassica napus with soybean isoflavone synthase. Plant Cell Rep., 30: 1435-1442. DOI: 10.1007/s00299-011-1052-8

Li, X., X. Li, M.J. Gao, H.Y. Pan and D.J. Cui et al., 2010. Purple canola: Arabidopsis PAP1 increases antioxidants and phenolics in Brassica napus leaves. J. Agric. Food Chem., 58: 1639-1645. DOI: $10.1021 / \mathrm{j} 1903527 \mathrm{y}$

Liu, C.J., J.W. Blount, C.L. Steele and R.A. Dixon, 2002. Bottlenecks for metabolic engineering of isoflavone glycoconjugates in Arabidopsis. Proc. Natl. Acad. Sci. USA, 99: 14578-14583. PMID: 12384577

Liu, R., Y. Hu, J. Li and Z. Lin, 2007. Production of soybean isoflavone genistein in non-legume plants via genetically modified secondary metabolism pathway. Metab. Eng., 9: 1-7. PMID: 17029902

Lonnerdal, B., 2002. Expression of human milk proteins in plants. J. Am. Coll. Nutr., 3: 218S-221S.

Mandal, S.M., D. Chakraborty and S. Dey, 2010. Phenolicacidsact as signalingmoleculesinplantmicrobesymbioses. Plant Signal. Behav., 5: 359-368. PMID: 20400851

Manoharan, M. and L.S. Dahleen, 2002. Genetic transformation of the commercial barley (Hordeum vulgare L.) cultivar Conlon by particle bombardment of callus. Plant Cell Rep., 21: 76-80.

Muir, S.R., G.J. Collins, S. Robinson, S. Hughes and A. Bovy et al., 2001. Over expression of petunia chalcone isomerase in tomato results in fruit containing increased levels of flavonols. Nat. Biotechnol., 19: 470-474. PMID: 11329019

Murashige, T. and F. Skoog, 1962. A revised medium for rapid growth and bio assays with tobacco tissue cultures. Physiol. Plant., 15: 473-497. DOI: $10.1111 /$ j.1399-3054

Prasad, S., S. Phromnoi, V.R. Yadav, M.M. Chaturvedi and B.B. Aggarwal, 2010. Targeting inflammatory pathways by flavonoids for prevention and treatment of cancer. Planta Med., 76: 1044-1063. DOI: 10.1055/s-0030-1250111

Rathburn, H.B., J. Song and C. Hedgcoth, 1993. Cytoplasmic male sterility and fertility estoration in wheat are not associated with rearrangements of mitochondrial DNA in the gene regions for cob, coxII,orcoxI. Plant Mol. Biol., 21: 195-201. PMID: 8425048 
Rimando, A.M., Z. Pan, J.J. Polashock, F.E. Dayan and C.S. Mizuno et al., 2012. Inplanta production of the highly potent resveratrol analogue pterostil-bene via stilbene synthase and O-methyltransferase coexpression. Plant Biotechnol. J., 10: 269-283. DOI: 10.1111/j.1467-7652.2011.00657.x

Romer, S., P.D. Fraser, J.W. Kiano, C.A. Shipton and N. Misawa et al., 2000. Elevation of the provitamin A content of transgenic tomato plants. Nat. Biotechnol., 18: 666-669. PMID: 10835607

Sevenier, R., I.V.D. Meer, R. Bino and A. Koops, 2002. Increased production of nutriments by genetically engineered crops. J. Am. Coll. Nutr., 21: 199-204S. PMID: 12071305

Shih, C.H., Y. Chen, M. Wang, I.K. Chu and C. Lo, 2008. Accumulation of isoflavone genistin in transgenic tomato plants overexpressing a soybean isoflavone synthase gene. J. Agric. Food Chem., 56: 5655-5661. DOI: $10.1021 / \mathrm{jf} 800423 \mathrm{u}$

Sreevidya, V.S., C.S. Rao, S.B. Sullia, J.K. Ladha and P.M. Reddy, 2006. Metabolic engineering of rice with soybean isoflavone synthase for promoting nodulation gene expression in rhizobia. J. Exp. Botany, 57: 1957-1969. PMID: 16690627

Venkatramesh, M., D.R. Corbin, G.B. Bhat, S.S. Boddupalli and R.J. Grebenok, 2000. Transgenic plants containing altered levels of sterol compounds and tocopherols. International and National Patent Collections.

Verdan, A.M., H.C. Wang, C.R. Garcia, W.P Henry and J.L. Brumaghim, 2011. Iron binding of 3hydroxychromone, 5-hydroxychromone and sulfonatedmorin: Implications for the antioxidant activity of flavonols with competingmetalbindingsites. J. Inorg. Biochem., 105: 1314-1322. DOI: 10.1016/j.jinorgbio.2011.07.006
Wang, X., 2011. Structure, function and engineering of enzymes inisoflavonoid biosynthesis. Funct. Integr. Genom., 11: 13-22. DOI: 10.1007/s10142-010-0197-9

Wei, S., X. Li, M.Y. Gruber, R. Li and R. Zhou et al., 2009. RNAi-mediated suppression of DET1 alters the levels of carotenoids and sinapate esters in seeds of Brassica napus. J. Agric. Food Chem., 57: 5326-5333. DOI: $10.1021 / \mathrm{jf} 803983 \mathrm{w}$

Ye, X., S. Al-Babili, A. Kloti, J. Zhang and P. Lucca et al., 2000. Engineering the provitamin a (betacarotene) biosynthetic pathway into (CarotenoidFree) rice endosperm. Science, 287: 303-305. PMID: 10634784

Yu, O., W. Jung, S. June, R.A. Croes and G. Fader et al., 2000. Production of the isoflavones genistein and daidzein in non-legume dicot and monocot tissues. Plant Physiol., 124: 781-787. PMID: 11027726

Yu, O., J. Shi, A.O. Hession, C.A. Maxwell, B. McGonigle and J.T. Odell, 2003. Metabolic engineering to increase isoflavone biosynthesis in soybean seed. Phytochemistry, 63:753-63. PMID: 12877915

Zhang, J., S. Subramanian, G. Stacey and O. Yu, 2009. Flavonesand flavonols play distinct critical roles during nodulation of Medicago truncatula by Sinorhizobium meliloti. Plant J., 57: 171-183. DOI: 10.1111/j.1365-313X.2008.03676.x 